University of New Orleans

ScholarWorks@UNO

6-1987

\title{
Leafcutting Ant Diet Selection: The Role of Nutrients, Water, and Secondary Chemistry
}

Jerome J. Howard

University of New Orleans, jjhoward@uno.edu

Follow this and additional works at: https://scholarworks.uno.edu/biosciences_facpubs

Part of the Biology Commons

\section{Recommended Citation}

Howard, J.J. (1987). Leafcutting ant diet selection: the role of nutrients, water, and secondary chemistry. Ecology 68 (3): 503-515.

This Article is brought to you for free and open access by the Department of Biological Sciences at ScholarWorks@UNO. It has been accepted for inclusion in Biological Sciences Faculty Publications by an authorized administrator of ScholarWorks@UNO. For more information, please contact scholarworks@uno.edu. 


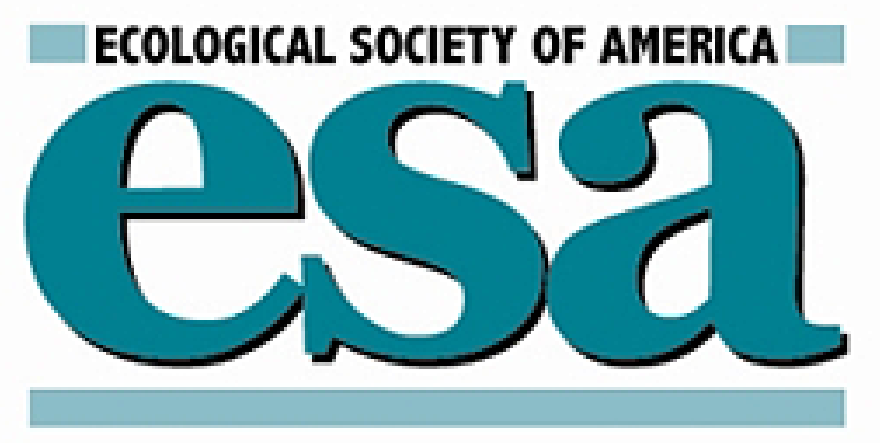

Leafcutting Ant Diet Selection: The Role of Nutrients, Water, and Secondary Chemistry Author(s): Jerome J. Howard

Reviewed work(s):

Source: Ecology, Vol. 68, No. 3 (Jun., 1987), pp. 503-515

Published by: Ecological Society of America

Stable URL: http://www.jstor.org/stable/1938455

Accessed: 08/08/2012 12:39

Your use of the JSTOR archive indicates your acceptance of the Terms \& Conditions of Use, available at http://www.jstor.org/page/info/about/policies/terms.jsp

JSTOR is a not-for-profit service that helps scholars, researchers, and students discover, use, and build upon a wide range of content in a trusted digital archive. We use information technology and tools to increase productivity and facilitate new forms of scholarship. For more information about JSTOR, please contact support@ jstor.org. 


\title{
LEAFCUTTING ANT DIET SELECTION: THE ROLE OF NUTRIENTS, WATER, AND SECONDARY CHEMISTRY ${ }^{1}$
}

\author{
JEROME J. HOWARD \\ Program in Evolutionary Ecology and Behavior, Department of Biology, University of Iowa, \\ Iowa City, Iowa 52242 USA
}

\begin{abstract}
The relationship of plant secondary chemistry, water content, and nutrient content to the palatability of leaves to the leafcutting ant Atta cephalotes was determined in a study of individuals from 50 woody plant species in tropical dry forest of Costa Rica. The study took place during the yearly period of maximum leaf harvest, in the early rainy season. The palatability of plants was determined by presenting leaf disks to ants on active foraging trails of three ant colonies. The distribution of several classes of polar secondary compounds in leaf samples was determined using chemical spot tests, and that of antdeterrent nonpolar compounds using laboratory bioassays of plant nonpolar extracts. Nitrogen, energy, and water availability in leaves were assessed using quantitative analyses.

Plants of high relative palatability generally lacked deterrent nonpolar extracts but did contain hydrolyzable tannins; the opposite was true for plants of low palatability. Little or no relationship was found to exist between plant palatability and measures of leaf nitrogen, energy content, and moisture content, or the presence of alkaloids and condensed tannins in leaves. No statistically significant interactions among leaf characteristics were found. The number of leaf disks harvested by ant colonies decreased during the study period. This decrease was unrelated to nutrient and moisture availability in leaves, but may be related to changes in secondary chemistry over the course of the season. Although plants were not equally palatable to all colonies tested, there was no evidence that colony-to-colony differences in plant preferences were related to the plant characteristics studied. Overall, the results suggest that plant secondary chemistry is the best predictor of plant species utilization by leafcutting ants.
\end{abstract}

Key words: ant-deterrent compounds; antiherbivore defenses; Atta cephalotes; bioassay; Costa Rica; herbivory; leaf palatability; nonpolar extracts; plant secondary chemistry; tropical deciduous forest, tropical woody plants.

\section{INTRODUCTION}

Generalist insect herbivores face the challenge of selecting an appropriate diet from among many plant species that may vary in abundance and quality. All herbivores encounter variation in nutrient availability in plants, but generalists also encounter plants defended by a variety of chemical and physical traits, and must evaluate each of these as well as the availability of plant nutrients when assessing plant quality (Beck 1965, Scriber 1984). Most work on diet selection by generalist insect herbivores has emphasized the avoidance of plants containing deleterious secondary chemicals (Jermy 1966, Harley and Thorsteinson 1967, Schoonhoven and Derksen-Koppers 1976). However, nutrients may also be positive feeding stimuli for generalists (Kennedy and Booth 1951, Thorsteinson 1958, 1960, Soo Hoo and Fraenkel 1966), and interactions between allelochemicals and nutrients in herbivore foods have been documented (Reese 1979). Due to the difficulty of measuring many relevant plant characteristics in many potential resource species, few studies have attempted to sort out the relative importance of

\footnotetext{
' Manuscript received 2 April 1986; revised 8 September 1986; accepted 10 September 1986.
}

different plant characteristics in diet selection by polyphagous insects.

Leafcutting ants of the genus Atta (Formicidae: Attini) are among the most common herbivores in neotropical forests, and are among the most polyphagous insects known. A single colony may harvest many kilograms of leaf material per year (Lugo et al. 1973, Haines 1978), and cut as many as 50 plant species in its foraging area (Cherrett 1968, Rockwood 1976, Shepherd 1985). Attack by leafcutting ants may significantly reduce the fitness of individual plants (Rockwood 1973, Marquis 1984), and may potentially alter the structure of neotropical forests (Gilbert 1980). The ants use solid leaf material to culture a symbiotic fungus which is the sole source of food for larvae, but adult ants may obtain $>90 \%$ of their energy requirements by directly imbibing liquid from cut and crushed leaf tissues (Quinlan and Cherrett 1979). Although leafcutters attack many species of plants, they strongly prefer some species over others (Rockwood 1976, Blanton and Ewel 1985), and these preferences change over time (Rockwood 1975, 1976). Many species are cut only seasonally, with new leaves being preferred to old (Fennah 1950, Rockwood 1975, 1976).

Leafcutting ants are thus important generalist her- 
bivores of the Neotropics, for which selectivity in diet is well known. However, the basis for the preference of some plant species over others remains obscure. Field studies have found plant palatability or the probability of attack by leafcutting ants to be related to the density or "toughness" of leaves (Cherrett 1972, Waller $1982 a, b)$, water content (Cherrett 1972, Bowers and Porter 1981), the presence or absence of latex systems (Stradling 1978), and plant secondary chemistry (Waller 1982b, Hubbell et al. 1984). Laboratory studies have shown that leafcutters are capable of discriminating among leaves on the basis of nutrients and secondary chemistry (Cherrett and Seaforth 1970, Barrer and Cherrett 1972, Littledyke and Cherrett 1975, 1976, 1978, Mudd et al. 1978). However, no general understanding of diet selection by leafcutting ants in nature has emerged from this work because most studies have so far focussed on a single plant characteristic or on a single plant species. This level of analysis yields only limited insights into a system in which a generalist herbivore must choose from among many plant species, and where it is possible that several factors may contribute to such choices.

Here I report the results of an experimental field study of the effects of water content, nutritional quality, and secondary chemistry on the palatability of many species of plants to the leafcutting ant Atta cephalotes L. I determined the relationship between leaf composition and palatability to answer the following questions:

1) What characteristics are most important in determining the palatability of leaves of different plant species in nature?

2) Do leaf characteristics affect palatability in the same way for different ant colonies?

I studied the distribution of six classes of plant secondary chemicals and measured leaf water content and four indices of nitrogen and energy availability in individuals of 50 plant species. I determined the palatability of these plants to each of three leafcutting ant colonies during a 10 -wk period, and analyzed the relationship between plant chemical characteristics and palatability during this period of time.

Some previous studies have suggested on the basis of bioassays of crude polar and nonpolar plant extracts that leafcutting ants are more sensitive to nonpolar allelochemicals such as terpenoids than to polar compounds such as phenolics, alkaloids, and glycosides (Hubbell and Wiemer 1983, Hubbell et al. 1984). However, nutrients such as proteins and carbohydrates are present in crude polar extracts, and are generally absent from nonpolar extracts. Bioassays of crude polar extracts may thus underestimate the impact of polar allelochemicals on ant behavior if nutrients and secondary substances both affect the palatability of plants and plant extracts. In the present study I used bioassays to screen nonpolar plant extracts for deterrent allelochemicals, and specific chemical methods to obtain detailed information on the occurrence of several polar classes of secondary chemicals in plants.

\section{Study Site ANd Natural History}

The field study was carried out in tropical deciduous forest on the upper plateau of Santa Rosa National Park, Guanacaste Province, Costa Rica, from early June to early August 1983. The habitat consists of jaragua grass savannah (Hyperrhenia rufa), interspersed with patches of secondary forest. The study was centered on one 20-ha patch of secondary forest, aged 60-80 yr (D. Janzen, personal communication), and the surrounding areas of pioneering vegetation. The patch has a heterogeneous history of disturbance, with some parts being cleared pasture bounded by planted fencerow trees as recently as 20 yr ago. Approximately 190 woody plant species currently occur on the study site and $\approx 90$ species are at least locally common (S. P. Hubbell, personal communication). Colonies of Atta cephalotes occur at a density of $0.5-1.0$ colonies/ha in and around the study area, from areas of closed-canopy evergreen forest in mesic sites to highly insolated forest edge and pioneer-stage successional habitats.

Santa Rosa experiences a prolonged dry season from December to May, and most tree species shed their leaves for at least part of this time. Deciduous trees flush new leaves at the beginning of the rainy season in May or June, and by August these leaf crops are relativley mature. Evergreen trees usually replace a significant fraction of their leaves during the dry season, but continue to initiate new leaves during the rainy season. Patterns of resource use by leafcutting ants closely parallel seasonal changes in leaf production. Ants forage extensively on fallen leaves and flowers during the dry season when leaf availability is low (Rockwood 1975, S. P. Hubbell, personal communication). Foraging on leaves peaks at the onset and end of the rainy season when leaves are being produced or shed, and is relatively low during the mid-rainy season when the leaves of most trees are mature (Hubbell et al. 1984).

Annual rainfall at Santa Rosa is between 1500-2000 mm (Janzen 1983), but the 12 mo prior to the study were marked by reduced rainfall due to the effects of the 1982-1983 El Niño climatic fluctuation. Only 947 $\mathrm{mm}$ of rain fell from 1 June 1982 through 31 May 1983, compared with $2242 \mathrm{~mm}$ of rain for the same period during 1981-1982 (D. H. Janzen, personal communication). Rainfall during the period of the study appeared to be slightly less than usual, but not dramatically so (J. J. Howard, personal observation).

\section{Materials AND Methods}

Leaf preferences were measured during a 10 -wk period from the start of the rainy season in early June, to mid-August 1983, when leaf harvesting activity by leafcutting ants is at its yearly peak in Santa Rosa (Hubbell et al. 1984). The relative palatability of plant species to leafcutting ants is consistent throughout this period, 
despite a decline in overall foraging activity in midJuly and August (Hubbell et al. 1984). Three blocks of experiments were carried out, the first at the onset of the rains during the first $2 \mathrm{wk}$ of June, the second during the first 2 wk of July, and the third 9 wk after the start of the rains, during the first 2 wk of August. During each block of experiments I presented leaves from single individuals of each of 50 plant species to three colonies of leafcutting ants to determine palatability, and collected samples of each plant for analysis of water content, nutritional quality, and secondary chemistry.

Plants used in the study were the same individuals whose leaves had been previously assayed for the presence of ant-deterrent activity by Hubbell et al. (1984), with a few additions. I used 37 of the 42 individual plants tested by Hubbell et al. (1984), and added individuals of eight species that had been assayed for deterrent activity at a later date (Aegiphila martinicensis, Cedrela odorata, Enterolobium cyclocarpum, Lasianthaea fruticosa, Ocotea veraguensis, Sapium thelocarpum, Sapranthus palanga, and Spondias mombin). Five of the individual plants tested by Hubbell et al. (1984) either could not be relocated or had been destroyed or severely damaged by fire or trail maintenance activity, and were replaced with new individuals of the same species (Bombacopsis quinatum, Bursera simaruba, Malvaviscus arboreus, Paullinia cururu, and Randia echinocarpa). The 50 plant species studied represent about half of the common trees and shrubs in the study area, and were initially selected for screening without bias with respect to their palatability to leafcutting ants. One plant, Jacquinia pungens, sheds its leaves in the wet season, and bore leaves only during the June block of experiments.

I selected three leafcutting ant colonies for study, two in secondary forest (F1 and F2) and the third in a disturbed area at the edge of the park headquarters $(\mathrm{H})$. Ant colonies were selected on the basis of their large size and of previous experience which suggested that they were likely to forage actively throughout the experimental period. Despite this precaution, one of the colonies in the secondary forest became inactive in August, and was replaced with another colony in the same area (F3) for the August block of experiments. Several of the plants used in the study were located in the foraging area of the headquarters colony, but had not been cut by that colony during three rainy seasons of observation. None of the colonies in secondary forest had any previous experience with the individual plants used in the study, although conspecific plants of most species were present within their foraging range.

Leaves were collected for palatability measurements and chemical analyses from a single marked branch on each plant. I used sunlit branches whenever possible, and the same branch was sampled throughout the entire experimental period. I collected leaves by cutting terminal branchlets of small leaves, or by snapping off the petioles of large leaves at the point where they joined the stem. All palatability measurements were initiated within $30 \mathrm{~min}$ and completed within $2 \mathrm{~h}$ of the time of collection, prior to the appearance of observable changes in palatability at $\approx 3 \mathrm{~h}$ postcollection. After $\approx 3 \mathrm{~h}$ the absolute palatability of leaf disks decreases, and the relative palatability of plant species begins to vary (J. J. Howard, personal observation).

I measured the palatability of leaves by placing small $\left(30-\mathrm{mm}^{2}\right)$ leaf disks on active foraging trails, and counting the number of leaf disks picked up during a 15-min period. Disks were cut from leaves using a standard hand-held paper punch. Leaf disks from 810 plants at a time were randomly assigned positions on the trail and were simultaneously presented to foraging ants in a "smorgasbord" fashion (Hubbell and Wiemer 1983, Hubbell et al. 1984). Disks removed by ants were replaced immediately with a fresh disk of the same species. At the end of each 15-min period the number of disks removed was recorded, any remaining leaf disks were removed, and the order of leaf disks on the trail was altered. Leaf disks farthest from the entrance to the colony during one 15-min measurement period were placed closest to the colony entrance for the next measurement period. Four replicate measurements of palatability were made for each plant tested on each colony during a block of experiments.

Before and after each set of 15-min experiments I counted the number of ants passing a fixed point on the trail during three 1 -min periods. To prevent individual ants from repeatedly visiting the smorgasbord and inflating the palatability measurements for a single plant species, all experiments were carried out $\approx 30 \mathrm{~m}$ from the entrance to the colony. At an average walking rate of $1 \mathrm{~m} / \mathrm{min}$ (Lewis et al. 1974), it is unlikely that an ant could have completed a round trip more than once during a single test. In each experiment I included a standard of oat flakes soaked in a $10 \%$ sucrose solution, to control for variation in the number of ants on the trail from test to test.

To determine whether observed changes in palatability were produced by the methods used to collect leaves, I compared the palatability of 20 plants used in the study with that of conspecifics not in the study. These tests were carried out in mid-July on the colony in the disturbed area at the edge of park headquarters (colony $\mathrm{H}$ ). The conspecific plants were not attacked by leafcutting ants earlier in the same season, and had not been subjected to manipulative studies by other investigators for at least $1 \mathrm{yr}$ previously. Leaves from the conspecifics were collected exactly as previously described, and four replicate 15 -min palatability tests were run within $2 \mathrm{~d}$ of the tests on the plants in the study.

\section{Measurement of chemical characteristics}

Leaf samples for chemical analysis were usually collected at the same time as samples for palatability measurements, and in all cases were collected within $48 \mathrm{~h}$ of the tests. Samples taken after tests were completed were collected at the same time of day as those used 
for palatability measurements. Undamaged leaves (50$300 \mathrm{~g}$ ) were collected by cutting terminal branchlets or snapping off the petiole where it joined the branch. Samples received a preliminary air drying in mesh bags, and were then dried for $1-2 \mathrm{~h}$ in an oven at $40^{\circ} \mathrm{C}$. All samples were completely dried within $72 \mathrm{~h}$ of collection. After removing midribs and large veins, dried samples were crushed, packed in two layers of plastic bags, and stored in the dark until returned to Iowa. Leaf samples were then ground to pass a $150-\mu \mathrm{m}$ mesh sieve and were stored at $-20^{\circ}$ until analysis.

Water content of leaves was estimated for five leaves from each collection. Intact leaves from each plant were collected and weighed in the field. Each leaf was then individually tagged, dried, and stored in a plant press. Prior to reweighing in the laboratory, leaves were redried for $12 \mathrm{~h}$ at $100^{\circ}$ and stored in a desiccating jar until cool. Water content was calculated as: (mass in the field - mass in the laboratory)/mass in the field.

Two measures of nitrogen availability were determined for each sample: protein content and total nitrogen content. The protein content of leaves was determined in order to provide a relevant measure of nitrogen availability to leafcutting ants, which satisfy immediate nutritional requirements by imbibing liquid from cut and crushed leaves (Littledyke and Cherrett 1976, 1978). Total nitrogen content of leaves was thought to be a more relevant measure for the fungal mutualist of the ants, which may be able to utilize nitrogenous secondary chemicals as nitrogen sources (Littledyke and Cherrett 1976). Single measurements of total nitrogen were performed on a Perkin-Elmer elemental analyzer in the Department of Chemistry, University of Iowa. Protein content was measured in triplicate using a modification of the Bradford assay (S. Faeth, personal communication). Samples of leaf powder weighing 3-5 $\mathrm{mg}$ each were extracted twice with acetone to remove pigments and phenolics that may interfere with the assay. A $1-\mathrm{mL}$ aliquot of 0.1 $\mathrm{mol} / \mathrm{L} \mathrm{NaOH}$ was added to each sample; the samples were then allowed to stand at $25^{\circ}$ for $36-40 \mathrm{~h}$. A 200 $\mu \mathrm{L}$ aliquot of this extract was added to $5 \mathrm{~mL}$ of Coomassie brilliant blue (Biorad Corporation) and the absorbance at $595 \mathrm{~nm}$ was measured after $5 \mathrm{~min}$. Protein content was calculated from a calibration curve constructed on the same day as the assay, using bovine serum albumin (Sigma Chemical).

Two measures of energy availability were performed on each sample collected, to provide relevant estimates of the availability of energy to ants and to the fungus. Since ants obtain nutrients directly from-leaf liquids, I estimated energy availability by determining the total nonstructural carbohydrate of leaves. The fungus utilizes large amounts of cellulose (Martin and Weber 1969), and to estimate energy availability for the fungus I simply measured the dry mass of a standard-sized piece of leaf blade (harvestable biomass). The total nonstructural carbohydrate content of leaf samples was estimated in triplicate using a modification of the phenol-sulfuric acid method (Southgate 1976). Samples of leaf powder (3-5 mg each) were extracted with $10 \mathrm{~mL}$ double-distilled water for $1 \mathrm{~h}$ at $95^{\circ}$. A $1 \mathrm{~mL}$ aliquot of this aqueous extract was added to $1 \mathrm{~mL}$ of $5 \%$ (mass/ volume) phenol and $5 \mathrm{~mL}$ concentrated sulfuric acid, gently mixed, and allowed to cool for one-half hour. The absorbance was read at $490 \mathrm{~nm}$, and a set of absorbance-matched 15-mL cuvettes was used to process several samples at a time. The percent nonstructural carbohydrate was calculated as sucrose equivalents using a calibration curve constructed on the same day as the experiment using reagent-grade sucrose. The harvestable biomass of each leaf sample was estimated by obtaining the mean dry mass of a standard-sized section of leaf blade for each of five leaves from each sample. After determination of water content on labelled, dried leaf collections, I used a hole punch to obtain $30-\mathrm{mm}^{2}$ pieces of lamina from each leaf and weighed the pieces using a Cahn microbalance. I measured five pieces from each leaf whenever possible, but fewer pieces were obtained from small leaves.

Qualitative analyses for secondary chemical substances were carried out on each sample. I used wellknown qualitative methods to detect the presence or absence in plant tissues of several classes of polar compounds: tannins, alkaloids, cyanogens, and saponins. Hubbell et al. (1984) suggested that nonpolar compounds in plant lipid extracts (mostly terpenoids) strongly influence the preference of leafcutting ants for certain plants, and no suitable qualitative chemical test exists for this heterogeneous group. To test plant samples for the presence of lipophilic compounds that deter attack by leafcutters, I performed bioassays on captive ant colonies at the University of Iowa using the method of Hubbell et al. (1984). Bioassays were carried out on eight plants new to the survey and five plants that replaced individuals used by Hubbell et al. (1984). The remaining plants were assigned scores reported in Hubbell et al. (1984), since bioassays of new leaf collections yielded identical scores in eight of nine plants tested (D. F. Wiemer, personal communication).

Plant samples were extracted with chloroform, which removes nonpolar compounds such as terpenoids, fatty acids, and waxes, but leaves polar compounds such as tannins, phenolics, glycosides, and most classes of alkaloids. Ants were presented with 60 test rye flakes coated with the plant extract and 60 control flakes coated with solvent only, and allowed to pick up flakes until half of the control flakes were taken. The differential, control (C) - test (T), was analyzed using a modified binomial test (Hubbell et al. 1984). Results of the bioassays were scored as: $\mathrm{C}-\mathrm{T} \leq 0$, nondeterrent; $0<\mathrm{C}-\mathrm{T}<14$, slightly (but not significantly) deterrent; $14 \leq \mathrm{C}-\mathrm{T} \leq 23$, significantly deterrent $(P<.05)$; $\mathrm{C}-\mathrm{T}>23$, highly deterrent $(P<.001)$. For most of the plants in Hubbell et al. (1984) the difference (control - test) obtained in laboratory bioas- 
says is known to be nearly constant for leaves collected during the first $10 \mathrm{wk}$ of the rainy season (D. F. Wiemer, personal communication), but complete data for this period were not available for all 50 plant species. I assume that the control - test difference, and thus bioassay scores of $0-3$, are constant throughout the entire study in those plants for which this information is unavailable.

Other qualitative analyses were performed using standard techniques. The Feigl-Anger test for cyanogenesis (Feigl and Anger 1966) was performed in the field using freshly collected leaf tissue. Indicator paper was prepared in the laboratory by soaking filter paper in a solution of copper ethylacetoacetate and 4,4' -tetramethyldiaminodiphenylmethane dissolved in chloroform. Fresh leaf tissue was macerated and sealed in a vial with a piece of indicator paper. In the presence of $\mathrm{HCN}$ the paper turned a dark blue within a few hours. I tested samples for the presence of saponins by shaking $1 / 2 \mathrm{~g}$ of leaf powder in a test tube containing $5 \mathrm{~mL}$ of water. The presence of persistent foaming $(>15 \mathrm{~min}$ ) was taken to indicate the presence of saponins (Harbourne 1973).

Qualitative analyses of tannins and alkaloids in samples were adapted from the procedures of Gartlan et al. (1980). A sample of leaf powder $(\approx 1 \mathrm{~g})$ was extracted for $30 \mathrm{~min}$ in $5 \mathrm{~mL}$ of $1 \mathrm{~mol} / \mathrm{L}$ sulfuric acid at $95^{\circ}$. The filtered extract was tested for the presence of alkaloids with an iodine-potassium iodide solution, Mayer's and Dragendorff's reagents, and a 5\% aqueous solution of tannic acid (Cromwell 1955). The possible presence of alkaloids is indicated by the formation of precipitates with one or more of these solutions. Extracts that gave positive results with one or more of the solutions were treated to remove possible false positive results by neutralizing the remainder of the acid solution with ammonium hydroxide, and extracting the free alkaloid bases into chloroform. The chloroform was evaporated off and the residue redissolved in $1 \mathrm{~mol} / \mathrm{L}$ sulfuric acid. This solution was then retested with the four reagents, and a strong reaction with at least two of the four was scored as indicating the presence of alkaloids. Weak reactions with at least two of the reagents were scored as indicating the possible presence of small amounts of alkaloidal substances.

It has been suggested that hydrolyzable and condensed tannins differ in their biological effects on microorganisms and insects (Zucker 1983), and I elected to test for the presence of each of these classes in plant samples. Tannins were extracted from a second sample of leaf powder into aqueous acid exactly as described above. The acid extract was cooled, vigorously mixed with $3 \mathrm{~mL}$ of amyl alcohol, and the layers allowed to separate for $30 \mathrm{~min}$. The upper, alcohol layer was pipetted off and spotted onto Whatman No. 3 MM chromatography paper for one-dimensional chromatography in Forrestal solvent $(30: 3: 10$, acetic acid : $\mathrm{HCl}$ : water). Visible spots at $R_{f} 0.50$ and $R_{f} 0.30$ indicated the presence of cyanidin and delphinidin condensed tannins, and UV-fluorescent spots at $R_{f} 0.65$ and $R_{f}$ 0.34 indicated the presence of gallo- and ellagitannins. Samples that were positive for cyanidin and/or delphinidin were scored as positive for condensed tannins, and those that were positive for gallo- and/or ellagitannins were scored as positive for hydrolyzable tannins (Harbourne 1973).

\section{Statistical analysis}

Analyses were performed using the SAS statistical package at the University of Iowa computing center. Because some plant characteristics were measured quantitatively and others qualitatively, an analysis of covariance was used to determine the relationship of plant characteristics to palatability. Analysis of covariance has a number of assumptions, which were examined to verify that this method was appropriate for the data set. The ANCOVA residuals were examined for normality, and a log transform of the dependent variable (number of leaf disks harvested, +1 ) and was found to provide an acceptable transformation and homogeneous residuals plot. Residuals were found to be uncorrelated with continuous variables (covariates), and residual variances were approximately equal among class variables (treatments). With the exception of total nitrogen (for which assays were unreplicated) the measurement error of the continuous variables is small, and I assume that the assumption of errorless measurement of covariates is adequately met. Regressions of the log-transformed dependent variable on the covariates are all linear, and show no improvement by adding higher order terms.

An additional assumption required for interpretation of the significance of covariates (but not for ANCOVA to test treatment effects) is that continuous variables are not highly intercorrelated (Neter et al. 1985). The existence of high correlations among continuous variables causes inflation in the variance of regression coefficients and makes them unreliable. Correlation coefficients among continuous variables were moderate, but variance inflation factors for these variables were all $<2$, indicating that the variables were sufficiently independent of one another to include all of them in the model (Neter et al. 1985, SAS Institute 1982).

I first ran an exploratory analysis of covariance to test the significance of the main effects of plant characteristics on palatability, and of all one-way interactions of characteristics with each other and with the month of the experiment. Because of the large number of effects in the initial model I set a conservative significance level of $P<.01$ as the minimum level for inclusion of interactions among leaf characteristics in subsequent analyses. All nonsignificant interactions were dropped, and the analysis was rerun including main effects, interactions of characteristics and month, and other significant interactions. The main effects yield 
TABLE 1. Analysis of variance on the palatability of plants to Atta during three monthly blocks of experiments.

\begin{tabular}{lrcrrr}
\hline \hline Source of variation & df & Sum of squares* & Mean square & \multicolumn{1}{c}{$F$} & $P$ \\
\hline Model & 147 & 86.22 & 0.58 & 3.32 & $<.001$ \\
Month & 2 & 10.64 & 5.32 & 31.10 & $<.001$ \\
Species & 49 & 58.85 & 1.20 & 6.79 & $<.001$ \\
Species $\times$ month & 96 & 16.40 & 0.17 & 0.97 & .5704 \\
Error & 296 & 52.34 & 0.18 & & \\
Total & 443 & 138.56 & & & \\
\hline
\end{tabular}

* Type IV sums of squares for effects in the model.

information on the overall importance of each characteristic during the experimental period, while interactions with month yield information on the consistency of these effects over time.

Although palatability measurements were organized into four 15-min periods, measurements on a single colony are not completely independent of one another. In addition, the treatments (presence or absence of secondary chemical classes) are not true experimental treatments. For these reasons I chose to pool the four 15-min measurements on each plant on each colony to obtain hourly totals of leaf disk harvest. This yielded three palatability measurements per month on each plant, and provides a relatively conservative test of the overall relationship of palatability to plant characteristics. Although Hubbell et al. (1984) divided the number of leaf disks taken in a choice test by the number of oat flakes taken to obtain an index of palatability, this produced residuals from the ANCOVA that were difficult to normalize. Instead, I used the number of sugar-coated oat flakes picked up during each choice test as a covariate in the ANCOVA.

Because colony F2 was replaced with colony F3 in August, I tested for colony differences using two subsets of the data (colonies H, F1, and F2 during June and July, and colonies $\mathrm{H}$ and $\mathrm{F} 1$ during June, July, and August). I treated each 15-min palatability measurement as a separate observation in this analysis. The model in this case contained all main effccts and all interactions of leaf characteristics with the colonies tested. Interactions of leaf characteristics with colony provide information on the extent to which the effect of leaf characteristics on palatability differs from colony to colony.

\section{RESULTS}

\section{Palatability measurements}

Nearly 4000 leaf disks of the 50 plants were harvested by the four colonies of leafcutting ants tested during the summer. An analysis of variance on leaf disk harvest during the three experimental periods revealed strong differences in palatability (leaf disks harvested per test) among plants and among the monthly blocks of experiments (Table 1). The lack of a significant plant $\times$ month interaction in the overall analysis (Table 1) indicates that plants maintained the same approximate rank-ordering of palatability throughout the 10-wk experimental period. The number of disks harvested in the monthly experimental blocks decreased throughout the summer (Table 2), paralleling the decrease in natural foraging of colonies observed during this period (Hubbell et al. 1984). Despite the decrease in leaf disks harvested, the number of ants foraging during palatability tests was identical in June and August, and the number of oat flakes picked up per test increased slightly over the 10-wk study period (Table 2). The observed decrease in leaf disks harvested might be due to changes induced by the method of collecting leaves from plants. However, the comparison of manipulated plants with nonmanipulated conspecifics shows no consistent effect of previous leaf collections on palatability (Table 3 ).

Two subsets of the data were analyzed to determine if colonies differed in their responses to plant species presented in palatability tests: data from colonies F1, $\mathrm{F} 2$, and $\mathrm{H}$ in the June and July experimental blocks, and data from colonies $\mathrm{F} 1$ and $\mathrm{H}$ in all three experimental blocks. Both subsets showed a significant col-

TABLE 2. Patterns of leaf disk harvest and ant activity in hour-long experiments during three experimental periods $(\bar{X} \pm 1$ SD). Entries in the same row followed by different superscript letters are significantly different $(P<.05$, Tukey's HSD test).

\begin{tabular}{|c|c|c|c|}
\hline & \multicolumn{3}{|c|}{ Experimental period } \\
\hline & June & July & August \\
\hline Total leaf disks harvested & 1991 & 1043 & 892 \\
\hline No. disks per species & $\begin{aligned} 39.82 & \pm 38.36^{\mathrm{a}} \\
(n & =50)\end{aligned}$ & $\begin{aligned} 21.29 & \pm 35.71^{\mathrm{b}} \\
(n & =49)\end{aligned}$ & $\begin{array}{c}18.20 \pm 23.39^{\mathrm{b}} \\
(n=49)\end{array}$ \\
\hline Ants per minute* & $\begin{array}{c}102.3 \pm 62.0^{\mathrm{a}} \\
(n=72)\end{array}$ & $\begin{array}{c}147.1 \pm 56.7^{\mathrm{b}} \\
(n=72)\end{array}$ & $\begin{array}{c}101.7 \pm 54.0^{\mathrm{a}} \\
(n=54)\end{array}$ \\
\hline Oat flakes harvested & $\begin{array}{c}58.87 \pm 19.56^{\mathrm{a}} \\
(n=16)\end{array}$ & $\begin{aligned} 67.73 & \pm 18.94^{\mathrm{a} \cdot \mathrm{b}} \\
(n & =11)\end{aligned}$ & $\begin{array}{c}78.67 \pm 36.40^{\mathrm{b}} \\
(n=9)\end{array}$ \\
\hline
\end{tabular}

* Ants per minute is the mean number of ants passing the bioassay site. 
TABLE 3. Analysis of variance on the effect of prior leaf collection on the palatability of plants to Atta.

\begin{tabular}{lrrccc}
\hline \hline Source & df & $\begin{array}{r}\text { Sum of } \\
\text { squares }\end{array}$ & $\begin{array}{c}\text { Mean } \\
\text { square }\end{array}$ & $F$ & $P$ \\
\hline Treatment & 1 & 5.63 & 5.63 & 0.63 & .429 \\
Error & 158 & 1414.28 & 8.95 & & \\
Total & 159 & 1419.90 & & & \\
\hline
\end{tabular}

ony effect, suggesting that colonies did differ from one another (Table 4). This was partly because colony F1 consistently harvested fewer leaf disks than did the other colonies (Fig. 1), but the significant interaction between species and colony also suggests that individual plant species are not equally palatable to all colonies (Table 4).

The extent of these palatability differences is revealed by calculations of the proportional overlap in leaf disk harvest between colonies (Colwell and Futuyma 1971). The proportional overlap between pairs of colonies was $\approx 0.66$ in all cases, indicating that colonies differed moderately in their patterns of leaf disk harvest (Table 5).

\section{Plant chemistry}

Quantitative measures of nitrogen, energy, and moisture availability did not vary uniformly during the 3 mo of the experiment. One-way ANOVAs on mean levels of the five measures during the three experimental periods revealed no significant changes in protein and harvestable biomass (dry mass per unit area of leaf lamina), and significant decreases in total nitrogen, nonstructural carbohydrate, and water (Table 6). An analysis of simple correlations among the quantitative variables revealed only three strong correlations: nitrogen content was positively correlated with protein content $\left(r^{2}=0.37, P<.0001\right)$ and water content $\left(r^{2}=0.25, P<.005\right)$, while harvestable biomass was inversely correlated with water content $\left(r^{2}=-0.54\right.$, $P<.0001$ ).

Qualitative analyses of tannins were relatively consistent throughout the experimental period. Twentysix plants showed spots on chromatograms indicative of condensed or hydrolyzable tannins in at least one of the three samples analyzed. Plants that contained tannins generally showed tannin activity in all three samples collected during the summer. However, plants containing more than one structural class of tannins often gained or lost activity of one class.

Alkaloid measures were somewhat more variable, with plants of 24 species showing at least one strong reaction and 10 others showing at least one weak reaction. Only 7 of the 24 strongly active plants consistently showed alkaloidal activity (at least weak reactions in all three samples). Alkaloid scores tended to increase over the experimental period in 7 plants and decrease in 6 others, while 4 plants showed peaks in

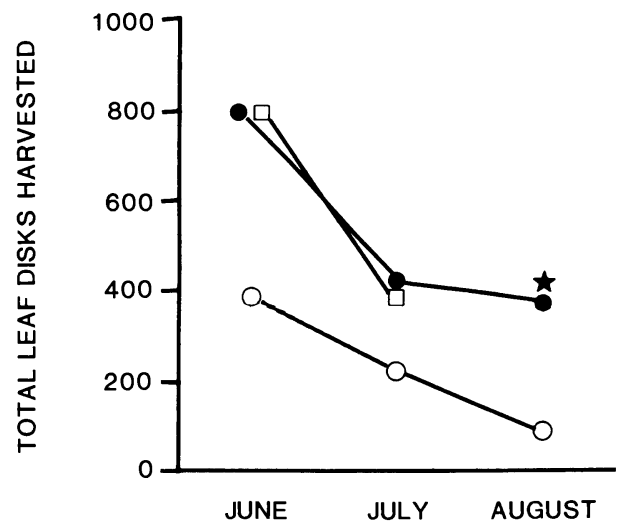

MONTH OF EXPERIMENT

Fig. 1. Total number of leaf disks harvested in field experiments by leafcutting ant colonies during three experimental periods. $\bullet=$ Colony $\mathrm{H} ; \mathrm{O}=$ Colony $\mathrm{F} 1 ; \square=$ Colony $\mathrm{F} 2 ; \star=$ Colony $\mathrm{F} 3$.

alkaloidal activity in the July collections. Overall, alkaloids were most common in the July block of experiments, in terms of both the number of species showing the presence of alkaloids, and the number showing strong alkaloid activity. Strong cyanogenesis was detected in all collections of Paullinia cururu, and persistent foaming indicative of saponins was detected in all collections of Pisonia macranthocarpa.

The activity of nonpolar extracts from the 13 plants tested was found to be highly consistent during the

TABLE 4. Analysis of variance on Atta colony responses to palatability tests, on two subsets of the data. All $P<.0001$.

\begin{tabular}{|c|c|c|c|c|}
\hline Source of variation & df & $\begin{array}{l}\text { Sum of } \\
\text { squares* }\end{array}$ & $\begin{array}{l}\text { Mean } \\
\text { square }\end{array}$ & $F$ \\
\hline \multicolumn{5}{|l|}{ Subset $1 \dagger$} \\
\hline Model & 152 & 125.62 & 0.83 & 14.39 \\
\hline Month & 1 & 11.71 & 11.71 & 203.86 \\
\hline Plant & 49 & 80.69 & 1.65 & 28.67 \\
\hline Colony§ & 2 & 7.46 & 3.73 & 15.11 \\
\hline Colony $\times$ plant & 98 & 24.19 & 0.25 & 4.30 \\
\hline Error & 1026 & 58.93 & 0.06 & \\
\hline Total & 1178 & 184.55 & & \\
\hline \multicolumn{5}{|l|}{ Subset $2 \ddagger$} \\
\hline Model & 103 & 96.90 & 0.94 & 16.98 \\
\hline Month & 2 & 8.97 & 4.40 & 79.35 \\
\hline Plant & 49 & 64.56 & 1.32 & 23.78 \\
\hline Colony§ & 1 & 10.64 & 10.64 & 42.92 \\
\hline Colony $\times$ plant & 49 & 12.15 & 0.25 & 4.47 \\
\hline Error & 1070 & 59.29 & 0.06 & \\
\hline Total & 1173 & 156.18 & & \\
\hline
\end{tabular}

* Type IV sums of squares for model effects.

$\dagger$ Colonies F1, F2, and $\mathrm{H}$ during the months of June and July.

$\ddagger$ Colonies F1 and $\mathrm{H}$ during the months of June, July, and August.

$\S F$ ratio constructed by use of [MS (colony)] $\div$ [MS (colony $\times$ plant)]; significance determined at df (colony) and $\mathrm{df}$ (colony $\times$ plant). 
TABLE 5. Similarity in preferences of leafcutting ant colonies for individuals of 50 tropical woody plant species, calculated as proportional overlap of leaf disk harvest by colonies.

\begin{tabular}{lcc}
\hline \hline Time period & Colonies & $\begin{array}{c}\text { Proportional } \\
\text { overlap* }\end{array}$ \\
\hline June-July & H vs. F1 & 0.668 \\
& H vs. F2 & 0.631 \\
June-August & F1 vs. F2 & 0.663 \\
& H vs. F1 & 0.644 \\
\hline
\end{tabular}

* See Colwell and Futuyma (1971) for formula.

study, in keeping with previous experience. Two of the plants chosen to replace damaged or dead individuals from the study of Hubbell et al. (1984), Bombacopsis quinatum and Bursera simaruba, differed from the original plants in the deterrency of their extracts. Nonpolar extracts from both of the original plants were deterrent in laboratory bioassays, while extracts of the replacements lacked deterrent activity. Deterrent activity of extracts from the other three replacement plants (Malvaviscus arboreus, Paullinia cururu, and Randia echinocarpa) was similar to that of extracts from the plants that they replaced.

The co-occurence of the four widespread classes of secondary compounds was examined by contingency table analysis. The occurrence of significantly deterrent nonpolar extracts $(C-T \geq 14)$ was independent of the occurrence of condensed tannins and alkaloids. However, hydrolyzable tannins occurred less often than expected in samples with deterrent nonpolar extracts (chi-squared $=12.6, P<.001$ ). Hydrolyzable and condensed tannins co-occurred more frequently than expected (chi-squared $=7.1, P<.001$ ), and both types of tannins showed a negative association with alkaloids in plant extracts (hydrolyzable tannins: chi-squared = 4.8, $P<.05$; condensed tannins: chi-squared $=14.0$, $P<.0001)$.

\section{Relationship of plant chemistry to palatability}

The analysis of covariance on overall patterns of palatability showed that leaf characteristics and the blocking variable explained about half of the variance in palatability (Table 7). Cyanide and saponin activity were omitted from the analysis because only one plant showed activity in each case. The exploratory data analysis found that no interactions among leaf characteristics met the criterion for inclusion in the analysis $(P<.01)$. Only main effects and interactions of leaf characteristics with the month of the experiment were included in the analysis of covariance. Among the main effects, the presence or absence of hydrolyzable tannins in extracts and the deterrency of nonpolar extracts were significantly correlated with the palatability of plant samples, as was the number of oat flakes harvested during each experiment. However, significance levels of .05-.01 must be interpreted with caution because of the large number of effects in the model, and hydrolyzable tannins cannot be considered from these results to have a strong influence on palatability. The palatability of samples that lacked deterrent nonpolar extracts $(C-T \leq 0)$ was much higher than that of samples whose nonpolar extracts were even slightly deterrent ( $\mathrm{C}-\mathrm{T}>0$ ) (Fig. 2). In contrast, samples containing hydrolyzable tannins were more palatable than those lacking such tannins (Fig. 2).

The correlation between leaf nonstructural carbohydrate content and palatability differed during the three experimental periods (nonstructural carbohydrate $\times$ month interaction, Table 7 ), but the significance of this effect was marginal. Separate regressions of carbohydrate content on palatability during each month showed that a significant, positive correlation with palatability existed only during August. This correlation explained $<3 \%$ of the variance, indicating a weak though significant relationship between nonstructural carbohydrate content and palatability.

\section{Chemistry and colony-to-colony differences in palatability}

Although plants were not equally palatable to all colonies (colony $\times$ species effect, Table 4 ), there was little apparent relationship between the leaf characteristics studied and colony-to-colony variation in palatability. Analysis of covariance using subset 1 of the data showed no significant interactions between colonies and leaf characteristics. Results from subset 2 of the data revealed that ant colonies differed only in their reactions to plants containing slightly deterrent nonpolar extracts $(P<.01)$

TABLE 6. Mean levels $( \pm 1 \mathrm{SD})$ of nutrients and water of individuals of 50 tropical woody plant species during three experimental periods. Entries in the same row followed by different superscript letters are significantly different $(P<.05$, Tukey's HSD test).

\begin{tabular}{|c|c|c|c|}
\hline & \multicolumn{3}{|c|}{ Experimental period } \\
\hline & June & July & August \\
\hline Protein ( $\%$ dry mass) & $3.02 \pm 1.79^{a}$ & $22.53 \pm 1.19^{\mathrm{a}}$ & $2.51 \pm 1.78^{\mathrm{a}}$ \\
\hline Nitrogen ( $\%$ dry mass) & $3.56 \pm 1.38^{\mathrm{a}}$ & $2.71 \pm 0.80^{\mathrm{b}}$ & $2.57 \pm 1.10^{\mathrm{b}}$ \\
\hline Nonstruc. carbohydrate ( $\%$ dry mass) & $17.18 \pm 6.74^{a}$ & $18.21 \pm 6.56^{\mathrm{a}}$ & $13.87 \pm 5.11^{\mathrm{b}}$ \\
\hline Biomass $\left(\mathrm{mg} / \mathrm{cm}^{2}\right.$ leaf area) & $5.98 \pm 2.56^{\mathrm{a}}$ & $4.99 \pm 2.05^{\mathrm{a}}$ & $5.71 \pm 2.71^{\mathrm{a}}$ \\
\hline Water ( $\%$ wet mass) & $73.96 \pm 10.50^{a}$ & $73.17 \pm 8.23^{a}$ & $68.23 \pm 7.57^{b}$ \\
\hline
\end{tabular}



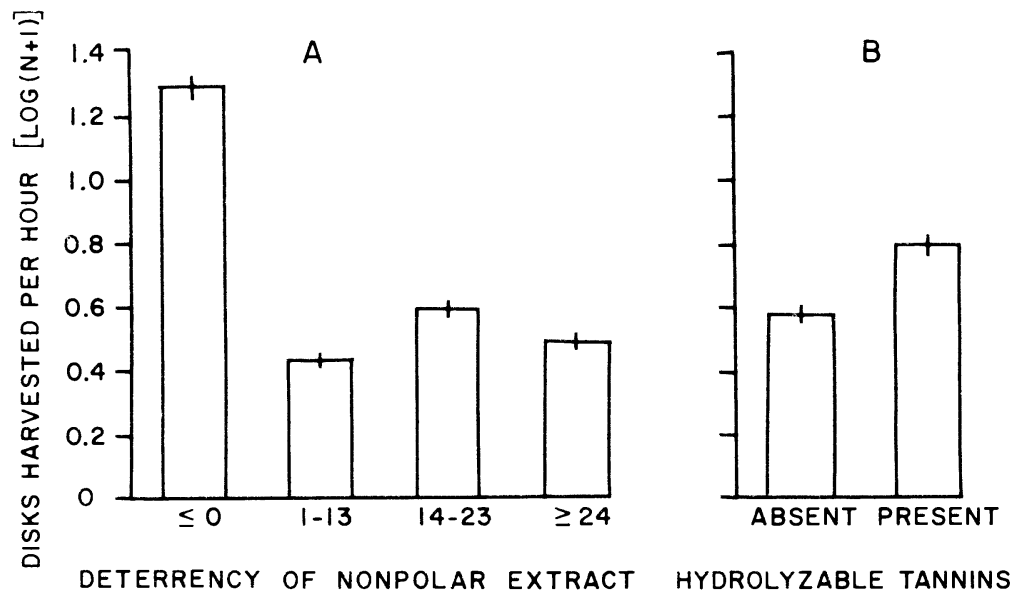

FIG. 2. Relationship of plant secondary chemicals to number of leaf disks harvested by three colonies of leafcutting ants in field experiments. (A) Deterrency of nonpolar extracts, determined by laboratory bioassays (control - test [extract-coated] rye flakes). (B) Presence or absence of hydrolyzable tannins, determined by paper chromatography. Short vertical line at the top of each bar indicates \pm 1 SE.

\section{DisCUSSION}

This study is the first to evaluate the relative inportance of many plant characteristics in the diet selection of a highly polyphagous insect herbivore. Previous studies involving leafcutting ants have found several factors to be related to diet selection, but these studies have largely been confined to a single plant species or characteristic. These studies have not addressed the relative importance of such factors, the possibility of interactions, or the possibility that significant correlations between palatability and any given plant characteristic might be due to covariance with a third, unstudied factor. By simultaneously measuring a number of leaf characteristics and analyzing their relationship to leaf palatability, this study provides in-

TABLE 7. Analysis of covariance on the relationship of plant chemical characteristics to leaf disk harvest in field experiments.

\begin{tabular}{|c|c|c|c|c|c|}
\hline Source of variation & df & $\begin{array}{l}\text { Sum of } \\
\text { squares* }\end{array}$ & $\begin{array}{l}\text { Mean } \\
\text { square }\end{array}$ & $F$ & $P$ \\
\hline $\begin{array}{l}\text { Model } \\
\text { Error } \\
\text { Total }\end{array}$ & $\begin{array}{r}41 \\
402 \\
443\end{array}$ & $\begin{array}{r}72.56 \\
56.00 \\
138.56\end{array}$ & $\begin{array}{l}1.77 \\
0.16\end{array}$ & 10.78 & $<.0001$ \\
\hline Blocking variable: & & & & & \\
\hline Month & 2 & 0.02 & 0.01 & 0.06 & .9436 \\
\hline $\begin{array}{l}\text { Covariate controlling for numb } \\
\text { Oat flakes }\end{array}$ & 1 & 12.93 & 12.93 & 78.76 & $<.0001$ \\
\hline $\begin{array}{l}\text { Main effects of chemistry: } \\
\text { Nonpolar extract deterrency } \\
\text { Alkaloids } \\
\text { Hydrol. tannins } \\
\text { Condensed tannins } \\
\text { Protein } \\
\text { Nitrogen } \\
\text { Nonstruc. carbohydrate } \\
\text { Harvest. bionass } \\
\text { Water content }\end{array}$ & $\begin{array}{l}3 \\
2 \\
1 \\
1 \\
1 \\
1 \\
1 \\
1 \\
1\end{array}$ & $\begin{array}{r}25.62 \\
0.58 \\
0.85 \\
0.08 \\
0.03 \\
0.15 \\
0.44 \\
0.15 \\
0.01\end{array}$ & $\begin{array}{l}8.54 \\
0.29 \\
0.85 \\
0.08 \\
0.03 \\
0.15 \\
0.44 \\
0.15 \\
0.01\end{array}$ & $\begin{array}{l}52.01 \\
1.76 \\
5.18 \\
0.47 \\
0.19 \\
0.92 \\
2.70 \\
0.92 \\
0.01\end{array}$ & $\begin{array}{l}<.0001 \\
.1728 \\
<.025 \\
.4950 \\
.6664 \\
.3371 \\
.1009 \\
.3374 \\
.9067\end{array}$ \\
\hline $\begin{array}{l}\text { Interactions of chemistry with } \\
\text { Month } \times \text { nonpolar extract } \\
\text { Month } \times \text { alkaloid } \\
\text { Month } \times \text { hyd. tannin } \\
\text { Month } \times \text { con. tannin } \\
\text { Month } \times \text { protein } \\
\text { Month } \times \text { nitrogen } \\
\text { Month } \times \text { nonstr. carbo. } \\
\text { Month } \times \text { biomass } \\
\text { Month } \times \text { water }\end{array}$ & $\begin{array}{l}6 \\
4 \\
2 \\
2 \\
2 \\
2 \\
2 \\
2 \\
2\end{array}$ & $\begin{array}{l}0.64 \\
0.86 \\
0.38 \\
0.80 \\
0.19 \\
0.43 \\
1.25 \\
0.04 \\
0.15\end{array}$ & $\begin{array}{l}0.11 \\
0.22 \\
0.19 \\
0.40 \\
0.09 \\
0.21 \\
0.62 \\
0.02 \\
0.07\end{array}$ & $\begin{array}{l}0.65 \\
1.31 \\
1.17 \\
2.43 \\
0.57 \\
1.31 \\
3.79 \\
0.12 \\
0.45\end{array}$ & $\begin{array}{c}.6882 \\
.2645 \\
.3107 \\
.0893 \\
.5647 \\
.2722 \\
<.025 \\
.8861 \\
.6400\end{array}$ \\
\hline
\end{tabular}

* Type IV sums of squares for effects in the model. 
formation on their relative importance in diet selection by leafcutting ants.

The results of this study support the idea that avoidance of certain plant secondary chemicals plays an important role in diet selection by leafcutting ants during the period of maximum leaf harvest in nature. There is little evidence that moisture content or nutritional constraints are of importance during this period. The lack of significant interactions among water content, nutrients, and chemical defenses suggests that such interactions do not play an important role during this period. This study may not be particularly sensitive to such interactions, in part due to the qualitative analysis of secondary chemicals used, and interactions may well be discovered using quantitative chemical methods. However, on the basis of this study I expect their impact on diet selection to be small relative to that of simple patterns of secondary chemistry. Overall, the significant relationship between secondary chemistry and palatability in this study is consistent with the view that avoidance of toxic secondary chemicals is the best predictor of plant species utilization by generalist insect herbivores (Jermy 1966, Schoonhoven and DerksenKoppers 1976).

\section{Plant secondary chemistry and palatability}

The correlation betwen palatability and the deterrency of nonpolar plant extracts is dramatic and consistent throughout the experimental period, suggesting that lipophilic secondary compounds may be the most important chemical factor determining plant palatability for leafcutting ants. Most ant-deterrent lipophilic compounds so far identified are derivatives of mono-, sesqui-, di-, and triterpenes, although natural concentrations in leaf tissues have not yet been determined in most cases (Wiemer 1985). Because of the uncertainty about natural concentrations, there has been some question as to whether the deterrency of these compounds in laboratory behavioral assays is representative of their role in natural foraging situations. The strong correlation observed in this study between deterrency of nonpolar extracts and plant palatability is evidence that these compounds are indeed an important influence on leafcutting ant foraging patterns. This is not the first study to find widespread feeding deterrent activity against insects in nonpolar extracts of plants (Bernays and Chapman 1977), and I suggest that this group of chemicals has been generally underemphasized in ecological studies.

The low palatability of leaves containing weakly deterrent nonpolar extracts $(0<\mathrm{C}-\mathrm{T} \leq 13)$ was unexpected, and plants characterized by this level of deterrency in laboratory bioassays deserve further study. It is possible that low palatability of these plants is due to other classes of secondary chemicals not analyzed here (e.g., simple phenolics, amines, nonprotein amino acids). Since thousands of individual tannins and alkaloids have been characterized, it is also possible that specific alkaloids or tannins present in these plants do strongly influence palatability, despite the lack of a general relationship between these chemical classes and palatability. An alternative possibility is that some plants contain deterrent or repellent lipids that are volatile or unstable, and are lost or degraded during sample preparation and storage prior to laboratory analysis.

Plants containing hydrolyzable tannins were highly palatable, but this in itself does not suggest that hydrolyzable tannins act as feeding stimulants to leafcutting ants, or as behavioral cues in locating palatable plants. The statistical significance of the correlation between hydrolyzable tannins and palatability must be considered marginal. In addition, plants that contained hydrolyzable tannins generally did not show significant deterrent activity in nonpolar extracts. It is likely that the high palatability of plants containing hydrolyzable tannins is a reflection of discrimination against plants containing lipophilic deterrents. It is noteworthy that Coley (1983) found that tannins and phenolics to be uncorrelated with overall rates of leaf damage from all insects in a study of lowland tropical rain forest. At this time the role of these substances in interactions of plants and herbivorous insects in tropical forests appears to be open to question.

Although the statistical analysis focussed only on chemical defenses widespread in the plants investigated, two plant species contained other defenses as well. Cyanogens and saponins were found in a single plant each, and these two plants, Paullinia cururu and $P i$ sonia macranthocarpa are among the least palatable of all plants tested in the study. In both cases other secondary chemical defenses were present as well, and it is unclear which of these varied defenses might deter leafcutting ants. At least some evidence exists to show that saponins alone are capable of deterring and possibly killing leafcutting ants (Febvay and Kermarrec 1986).

Several classes of polar secondary compounds were found to be unrelated to plant palatability in this study, and previous laboratory bioassays of crude plant extracts have shown leafcutting ant feeding deterrents to be more common in nonpolar than in polar extracts (Hubbell et al. 1984). Why should feeding deterrency be more closely associated with nonpolar, lipophilic compounds than with polar compounds? I suggest that the requirements of the ants' fungal mutualist may be the primary reason for discrimination against plants containing certain lipids. Fungi are sources of potent enzyme systems for detoxifying plant secondary chemicals, particularly phenolic substances (Martin 1979). It may be that the leafcutting ant fungus is well equipped to detoxify many nitrogenous and phenolic secondary compounds, but is vulnerable to some classes of nonpolar compounds. Most of the lipophilic deterrents characterized from plants avoided by leafcutting ants are terpenoids (Wiemer 1985), and numerous terpe- 
noids are known to possess significant fungistatic or fungitoxic activity (Stoessl 1970, 1983). Several of the unpalatable plant species in this study contain terpenoids that inhibit the growth of isolated cultures of the ant fungus (J. J. Howard, personal observation). However, the nonpolar nature of terpenoids makes them admirably suited for penetrating insect cuticle, and terpenoids may also possess insecticidal properties. Further experimentation on both ants and fungus will be required to determine the role played by the requirements of the fungus in the selection of leaves by leafcutting ants.

\section{Nutrients, water content, and palatability}

The overall lack of correlation between nutritional variables and palatability found in this study is consistent with the results of some previous studies of Atta cephalotes. Hubbell and Wiemer (1983) found no correlation between total nitrogen content and the palatability of plants to A. cephalotes, as measured in a field experiment. In addition, laboratory studies to date have found little evidence to suggest that $A$. cephalotes is attracted to either nitrogen or carbohydrate fractions isolated from plants (Cherrett and Seaforth 1970, Mudd et al. 1978). However, A. cephalotes does respond to pure solutions of mono- and disaccharides in the laboratory (Cherrett and Seaforth 1970, Littledyke and Cherrett 1975, 1978, Mudd et al. 1978), and the weak correlation of nonstructural carbohydrate and palatability at the end of this study suggests that nutrient content might be of greater importance in the latter half of the rainy season. Increased attention to nutritional quality in leaf selection might be expected if nutrients are less available in mature leaves, which predominated at the end of the study, than in young leaves. The increased harvest of sugar-coated oat flakes relative to leaf disks during August is consistent with this idea.

The lack of relationship between leaf water content and palatability is at variance with other studies of leafcutting ants that show either a positive (Cherrett 1972, Bowers and Porter 1981), or negative relationship (Blanton and Ewel 1985) between water content and the probability of leafcutting ant attack. Water content might be expected to be an important constraint on leafcutting ants, giving the greatly reduced rainfall in the study area in the previous year due to the 1982-1983 El Niño climatic fluctuation. However, the mean water content of leaves during the July experimental period $(73.17 \pm 8.23 \%)$ was substantially higher than that of 68 species at the same site measured during the same period in 1978 (66.25 $\pm 6.35 \%$ ) (Janzen and Waterman 1984), a year not marked by severe drought at Santa Rosa (D. H. Janzen, personal communication). It is possible that the water content of leaves measured in this study was higher than usual for some reason, and might still influence host plant selection under other circumstances, or in the dry season.

\section{Leaf chemistry and seasonal change in palatability}

The decrease in leaf disk harvest during the 10-wk experimental period parallels a decrease in foraging effort by leafcutting ants over the same period of time (Hubbell et al. 1984). These patterns are apparently related to changes in plant quality as leaves age, as no decreases were observed in the numbers of ants on trails or in the harvest of sugar-coated oat flakes, which remained constant in composition.

This study provides no immediate explanation for decreased harvest of leaf material over time, but does suggest that the relationship of this decrease to quantitative variation in plant secondary chemistry is worthy of investigation. Total nitrogen, non-structural carbohydrate content, and water content of leaves decreased during the study period, but were found to be uncorrelated with palatability in the analysis of covariance. The qualitative analyses of plant secondary chemistry carried out in this study do not provide sufficient information to test the idea that changes in palatability are related to changes in secondary chemical profiles. Quantitative analyses of plant secondary chemistry might well uncover differences in the concentrations of chemical defenses over this period of time, which might explain observed changes in plant palatability.

\section{Colony-to-colony variation in palatability}

Variation in the plant species preferred by leafcutting ant colonies has been reported for both Atta cephalotes and $A$. columbica (Rockwood 1976). Such variation may exist for a variety of reasons, including genetically determined differences in nutrient requirements or in the ability of ants or fungus to tolerate some secondary chemicals, physiological adaptation to different secondary chemical profiles in plants available to different colonies, simple preference for gustatory cues in plant species previously cut by some but not all colonies, and chance. The present study found moderate variation in plant palatability among ant colonies, which consistently shared only $\approx 0.66$ of their preferences according to measures of proportional overlap (Table 5). There was, however, no clear relationship between colony-to-colony differences in palatability and the plant characteristics measured. Only plant samples containing slightly deterrent nonpolar extracts varied in palatability to colonies, and only in one subset of the data. Since only 3-5 leaf disks/h were harvested from these plants, it is possible that this difference is in fact due to chance variation in rates of harvest. This possibility is supported by the observations that the effect was not consistent in both subsets of the data, and that ant colonies did not differ in their reactions to other nonpolar extracts. The plant characteristics evaluated in 
this study constitute an extensive, but not exhaustive, list of possible influences on ant foraging, and further study may establish a connection between colony-tocolony palatability differences and other plant characteristics not examined here.

\section{Other factors related to palatability}

Some insight into the effectiveness of latex systems at deterring leafcutting ant attack may be gained by comparing experimentally determined palatabilities with the frequency with which intact latex-bearing plants are attacked. Under the conditions of the choice tests latex systems are ineffective, because leaves detached from plants no longer exude latex. Five plants studied belonged to families characterized by latex systems, but only Ficus goldmanii (Moraceae), Sapium thelocarpum (Euphorbiaceae), and Stemmadenia obovata (Apocynaceae) exude appreciable amounts of latex when damaged. $S$. obovata was found to be relatively unpalatable, but both $F$. goldmanii and $S$. thelocarpum ranked among the 10 most palatable plants tested. ${ }^{2}$ I have never observed leafcutting ants attacking intact plants of either species at Santa Rosa, although senescent leaves of $S$. thelocarpum are often harvested after falling from the tree (J. J. Howard, personal observation). These observations suggest that latex systems may be the primary defenses against leafcutting ant attack in these two species.

The experiments reported here suggest that plan 1 secondary chemistry plays an important role in determining the palatability of plant species to the leafcutting ant Atta cephalotes during the period of maximum leaf harvest. However, the leaf disk bioassays used in this study preclude an assessment of the role of physical impediments to leaf cutting, such as toughness and trichome density, in determining vulnerability to leafcutting ant attack. Several studies have reported that leaf toughness is related to the probability of attack by leafcutting ants (Cherrett 1972, Waller 1982a, b), although none has explicitly addressed the role of lea1 trichomes. Further studies that address the relative influence of chemical and physical factors in diet selection by leafcutting ants will be of great interest. ${ }^{2}$

\section{ACKNOWLEDGMENTS}

I wish to thank L. Rohwer for assistance in the field, and S. Chouinard, R. Grant, N. Palumbo, and C. Sagers for assistance with the laboratory analyses. S. Baldwin conducted laboratory bioassays of new plant extracts. D. Janzen helped to identify plants and provided invaluable advice on the conduct of the field study. S. Faeth, R. Montgomery, M. Newlon, J. Poulton, and D. Wiemer helped to select and implement

${ }^{2}$ See ESA Supplementary Publicaton Service Document No. 8735 for an Appendix containing secondary chemistry, nutrient content, water content, and palatability to leafcutting ants, of individuals of 50 tropical woody plant species. For a copy of this document, contact the (senior) author or order from The Ecological Society of America, 328 East State Street, Ithaca, NY 14850-4318 USA. the chemical methods used. Advice on statistical issues was obtained from R. Kelley and R. Lenth of the University of Iowa Statistical Consulting Center. Comments by L. Johnson, S. Hubbell, D. Wiemer, S. Hendrix, J. Cazin, and two anonymous reviewers improved the manuscript. I am indebted to the Servicio de Parques Nacionales, Costa Rica, and especially to the personnel of the Santa Rosa National Park, for continuing interest in and support of this project. The Organization for Tropical Studies helped with logistics throughout the study. The study was made possible by funds from a Teaching-Research Fellowship from the University of Iowa, a Jesse Smith Noyes post-course award from the Organization for Tropical Studies, and National Science Foundation grants DEB 80-10638 and BSR 83-07105 to D. F. Wiemer and S. P. Hubbell. This work was completed in partial fulfillment of the requirements for the Ph.D. degree in the Department of Biology, University of Iowa.

\section{Literature Cited}

Barrer, P. M., and J. M. Cherrett. 1972. Some factors influencing the site and pattern of leaf-cutting activity in the ant Atta cephalotes L. Journal of Entomology (A) 47:1527.

Beck, S. D. 1965. Resistance of plants to insects. Annual Review of Entomology 10:207-232.

Bernays, E. A., and R. F. Chapman. 1977. Deterrent chemicals as a basis for oligophagy in Locusta migratoria (L.) Ecological Entomology 2:1-18.

Blanton, C. M., and J. J. Ewel. 1985. Leaf-cutting ant herbivory in successional and agricultural tropical ecosystems. Ecology 66:861-869.

Bowers, M. A., and S. D. Porter. 1981. Effect of foraging distance on water content of substrates harvested by Atta columbica (Guerin). Ecology 62:273-275.

Cherrett, J. M. 1968. The foraging behavior of Atta cephalotes L. (Hymenoptera: Formicidae). I. Foraging pattern and plant species attacked in tropical rain forest. Journal of Animal Ecology 37:387-403.

- 1972. Some factors involved in the selection of vegetable substrate by Atta cephalotes (L.) (Hymenoptera: Formicidae) in tropical rain forest. Journal of Animal Ecology 41:647-660.

Cherrett, J. M., and C. E. Seaforth. 1970. Phytochemical arrestants for the leaf-cutting ants, Atta cephalotes (L.) and Acromyrmex octospinosus (Reich) with some notes on the ants' response. Bulletin of Entomological Research 59:615625.

Coley, P. D. 1983. Herbivory and defensive characteristics of tree species in a lowland tropical forest. Ecological Monographs 53:209-233.

Colwell, R. K., and D. J. Futuyma. 1971. On the measurement of niche breadth and overlap. Ecology 52:567-576.

Cromwell, B. T. 1955. The alkaloids. Pages 367-516 in K. Paech and M. V. Tracey, editors. Modern methods in plant analysis. Volume 4. Springer-Verlag, Berlin, Germany.

Febvay, G., and A. Kermarrec. 1986. Prevention of feeding by Acromyrmex octospinosus with antifeedants from yams. Pages 247-259 in C. S. Lofgren and R. K. Vander Meer, editors. Fire ants and leaf-cutting ants: biology and management. Westview, Boulder, Colorado, USA.

Feigl, F., and V. Anger. 1966. Replacement of benzidine by copper ethylacetoacetate and tetra base as spot-test reagent for hydrogen cyanide and cyanogen. Analyst 91:282-284.

Fennah, R. G. 1950. Parasol ants, their life history and methods for their control. Proceedings of the Agricultural Society of Trinidad 50:312-326.

Gartlan, J. S., D. B. McKey, P. G. Waterman, C. N. Mbi, and T. T. Struhsaker. 1980. A comparative study of the phytochemistry of two African rain forests. Biochemical Systematics and Ecology 8:401-422. 
Gilbert, L. E. 1980. Food web organization and the conservation of neotropical diversity. Pages 11-33 in M. E. Soule and B. A. Wilcox, editors. Conservation biology. Sinauer Associates, Sunderland, Massachusetts, USA.

Haines, B. L. 1978. Element and energy flows through colonies of the leaf-cutting ant Atta columbica in Panama. Biotropica 10:270-277.

Harbourne, J. B. 1973. Phytochemical methods. Chapman and Hall, London, England.

Harley, K. L. S., and A. J. Thorsteinson. 1967. The influence of plant chemicals on the feeding behavior, development, and survival of the two-striped grasshopper, Melanoplus bivittatus (Say), Acrididae: Orthoptera. Canadian Journal of Zoology 45:305-319.

$\rightarrow$ Hubbell, S. P., J. J. Howard, and D. F. Wiemer. 1984 Chemical leaf repellency to an attine ant: seasonal distribution among potential host plant species. Ecology 65:10671076.

Hubbell, S. P., and D. F. Wiemer. 1983. Host plant selection by an attine ant. Pages 133-154 in P. Jaisson, editor. Social insects in the tropics. Volume 2. University of Paris Press, Paris, France.

Janzen, D. H. 1983. Costa Rican natural history. University of Chicago Press, Chicago, Illinois, USA.

Janzen, D. H., and P. G. Waterman. 1984. A seasonal census of phenolics, fibre and alkaloids in foliage of forest trees in Costa Rica: some factors influencing their distribution and relation to host selection by Sphingidae and Saturniidae. Biological Journal of the Linnean Society 21:439-454.

Jermy, T. 1966. Feeding inhibitors and food preference in chewing phytophagous insects. Entomologia Experimentalis et Applicata 9:1-12.

Kennedy, J. S., and C. O. Booth. 1951. Host alternation in Aphis fabae Scop. I. Feeding preference and fecundity in relation to the age and kind of leaves. Annals of Applied Biology 38:25-64.

$\rightarrow$ Lewis, T., G. V. Pollard, and G. C. Dibley. 1974. Rhythmic foraging in the leaf-cutting ant Atta cephalotes (L.) (Formicidae: Attini). Journal of Animal Ecology 43:129-141.

Littledyke, M., and J. M. Cherrett. 1975. Variability in the selection of substrate by the leaf-cutting ants Atta cephalotes (L.) and Acromyrmex octospinosus (Reich) (Formicidae: Attini). Bulletin of Entomological Research 65:33-47.

Littledyke, M., and J. M. Cherrett. 1976. Direct ingestion of plant sap from cut leaves by the leaf-cutting ants Atta cephalotes (L.) and Acromyrmex octospinosus (Reich) (Formicidae: Attini). Bulletin of Entomological Research 66: 205-217.

Littledyke, M., and J. M. Cherrett. 1978. Defense mechanisms in young and old leaves against cutting by the leafcutting ants Atta cephalotes (L.) and Acromyrmex octospinosus (Reich) (Hymenoptera: Formicidae). Bulletin of Entomological Research 68:263-271

$\rightarrow$ Lugo, A. E., E. G. Farnsworth, D. G. Pool, P. Jerez, and G. Kaufman. 1973. The impact of the leaf-cutting ant Atta columbica on the energy flow of a tropical wet forest. Ecology 54:1292-1301.

$\rightarrow$ Marquis, R. J. 1984. Leaf herbivores decrease fitness of a tropical plant. Science 226:537-539.

Martin, M. M. 1979. Biochemical implications of insect mycophagy. Biological Reviews of the Cambridge Philosophical Society $\mathbf{5 4 : 1 - 2 1}$

Martin, M. M., and N. A. Weber. 1969. The cellulose-utilizing capability of the fungus cultured by the attine ant Atta columbica tonsipes. Annals of the Entomological Society of America 62:1386-1387.

Mudd, A., D. J. Peregrine, and J. M. Cherrett. 1978. The chemical basis for the use of citrus pulp as a fungus garden substrate by the leafcutting ants Atta cephalotes (L.) and Acromyrmex octospinosus (Reich) (Hymenoptera: Formicidae). Bulletin of Entomological Research 68:673-685.

Neter, J., W. Wasserman, and M. H. Kutner. 1985. Applied linear statistical models. Second edition. Irwin, Homewood, Illinois, USA.

Quinlan, R. J., and J. M. Cherrett. 1979. The role of fungus in the diet of the leaf-cutting ant Atta columbica (L.). Ecological Entomology 4:151-160.

Reese, J. C. 1979. Interactions of allelochemicals with nutrients in herbivore food. Pages 309-330 in G. A. Rosenthal and D. H. Janzen, editors. Herbivores: their interaction with secondary plant metabolites. Academic Press, New York, New York, USA.

Rockwood, L. L. 1973. The effect of defoliation on seed production of six Costa Rican tree species. Ecology 54: 1363-1369.

$\rightarrow-1975$. The effects of seasonality on foraging in two species of leaf-cutting ants $(\mathrm{Atta})$ in Guanacaste province, Costa Rica. Biotropica 7:176-193.

- 1976. Plant selection and foraging patterns in two species of leaf-cutting ants (Atta). Ecology 57:48-61.

SAS Institute. 1982. SAS user's guide: statistics. 1982 edition. SAS Institute, Cary, North Carolina, USA.

Schoonhoven, L. M., and I. Derksen-Koppers. 1976. Effects of some allelochemics on food uptake and survival of a polyphagous aphid, Myzus persicae. Entomologia Experientalis et Applicata 19:52-56.

Scriber, J. M. 1984. Host-plant suitability. Pages 159-202 in W. J. Bell and R. T. Carde, editors. Chemical ecology of insects. Chapman and Hall, New York, New York, USA.

Shepherd, J. D. 1985. Adjusting foraging effort to resources in adjacent colonies of the leaf-cutter ant, Atta columbica. Biotropica 17:245-252.

Soo Hoo, C. F., and G. Fraenkel. 1966. The selection of food plants in a polyphagous insect, Prodenia eridania (Cramer). Journal of Insect Physiology 12:693-709.

Southgate, D. A. T. 1976. Determination of food carbohydrates. Applied Science, London, England.

Stoessl, A. 1970. Antifungal compounds produced by higher plants. Recent Advances in Phytochemistry 1:143-180.

- 1983. Secondary plant metabolites in preinfectional and postinfectional resistance. Pages 71-122 in J. A. Bailey and B. J. Deverall, editors. The dynamics of host defense. Academic Press, New York, New York, USA

Stradling, D. J. 1978. The influence of size on foraging in the ant Atta cephalotes, and the effect of some plant defense mechanisms. Journal of Animal Ecology 47:173-188.

Thorsteinson, A. J. 1958. Acceptability of plants for phytophagous insects. Pages 599-602 in Proceedings of the Tenth International Congress of Entomology, Montreal, 1956. Volume 2. Ottawa, Ontario, Canada.

1960. Host selection in phytophagous insects. Annual Review of Entomology 5:193-218.

Waller, D. A. 1982a. Leaf-cutting ants and live oak: the role of leaf toughness in seasonal and intraspecific host choice. Entomologia Experimentalis et Applicata 32:146-150.

- $1982 b$. Leaf-cutting ants and avoided plants: defences against Atta texana attack. Oecologia (Berlin) 52: 400-403.

Weber, N. A. 1972. Gardening ants: the attines. Memoirs of the American Philosophical Society 92.

Wiemer, D. F. 1985. Natural repellents of the leafcutter ants. Revista Latinoamericana de Quimica 16:98-102.

Zucker, W. V. 1983. Tannins: does structure determine function? An ecological perspective. American Naturalist 121:335-365. 